\title{
BNCC E O CURRÍCULO DE HISTÓRIA: interpretações docentes no contexto da prática
}

\author{
Francisco José Balduino da Silva \\ Secretaria da Educação do Estado do Ceará - SEDUC-CE \\ Jean Mac Cole Tavares Santos \\ Universidade do Estado do Rio Grande do Norte - UERN \\ Márcia Frota Fernandes \\ Universidade do Estado do Rio Grande do Norte - UERN
}

\begin{abstract}
Resumo
O presente artigo adentra na discussão sobre a Base Nacional Comum Curricular (BNCC) e sua tentativa de normatização do currículo para o Ensino Médio. Nos propomos neste trabalho, analisar como os professores de História interpretam as implicações da BNCC para o currículo de História. Nos valemos como suporte teórico-metodológico do ciclo de política de Ball e Bowe (1998) para analisarmos diferentes instâncias da produção do discurso em volta da BNCC e as traduções feitas pelos professores de História sobre as implicações que a Base trará para o currículo da disciplina, aliando nossa análise a discussões pautadas em leituras pós-estruturais para discutirmos a tentativa de normatização e homogeneização almejadas pela BNCC. O trabalho está organizado em três pontos: no primeiro discutimos os embates e acordos no contexto de influência que levaram a escrita da BNCC; no segundo ponto analisamos a BNCC e a produção de sentidos para o currículo no contexto da produção de texto e finalizamos o artigo com a análise das falas dos professores sobre quais as perspectivas que estes sujeitos têm sobre as implicações que a Base trará para o currículo de História no contexto da prática.
\end{abstract}

Palavras-chave: Base Nacional Comum Curricular (BNCC). Currículo. Ensino de História.

\begin{abstract}
This article addresses the discussion about the Brazilian National Common Curricular Base (BNCC) and its attempt concerning the standardization of the curriculum for High School. An analysis of how History teachers interpret the implications of the BNCC for the History curriculum was proposed. The theoretical and methodological support was given by the policy cycle of Ball and Bowe (1998) in order to analyze different instances of the discourse production around the BNCC and the perceptions by the History teachers about the implications that the Base will bring to the curriculum of the subject, combining this analysis with argumentations based on post-structural readings for the discussion of the attempt of standardization and homogenization sought by BNCC. The work is organized in three points: in the first, the clashes and agreements in the context of influence that led to the writing of the BNCC are discussed; in the second point the BNCC and the production of meanings for the curriculum in the context of the production of text are analyzed, and finally the article with the analysis of the teachers' statements about the perspectives which these subjects have in relation to the implications that the Base will bring to the curriculum in the practice context.
\end{abstract}

Keywords: Brazilian National Common Curricular Base. Curriculum. History Teaching. 


\section{Introdução}

Com o lançamento do documento preliminar da Base Nacional Comum Curricular (BNCC) em 2015 pelo Ministério da Educação (MEC), foi retomado um ponto levantado na Lei de Diretrizes e Bases da Educação Nacional (LDB, 9.394/96) que já preconizava em seu artigo 26 uma base nacional comum para o ensino fundamental e médio, este artigo foi alterado em 2013 pela Lei nº12.796 de 2013 e passou a contemplar a educação infantil também como nível a ser organizado por via de uma base nacional curricular (BRASIL, 2013). A discussão da Base encontrava-se sonolenta, mas não adormecida, uma vez que outras tentativas de regulamentação curricular já haviam sido aprovadas e disseminadas pelo Ministério da Educação (MEC), por via das Diretrizes Curriculares (2013) e os Parâmetros Curriculares Nacionais (PCN's - 1998).

Essa preocupação com o currículo compõe discussões que extrapolam as fronteiras nacionais, elegendo o currículo como elemento definidor de qualidade na educação, e para isso, órgãos governamentais chamam atenção para que o currículo seja organizado de forma atraente para os alunos (LOPES, 2012). Com isso, o Brasil agrupa-se a outros países da iberoamérica em volta de discursos de sucesso educacional por meio da definição de currículos capazes de orientar o trabalho de professores (DIAS, 2017).

Este movimento em prol do currículo de qualidade compõe-se a partir da lógica ligada à condição pós-moderna na qual vivemos, onde o saber passa a ser consumido e valorizado para ser trocado, deixando de existir por si próprio e perdendo valor de uso, o qual é sobreposto pelo valor de troca (LYOTARD, 2009), e mesmo que o conhecimento seja o centro do discurso "[...] podemos identificar sua vinculação ao caráter instrumental, quando tenta responder a questão da utilidade de sua utilização [...]” (DIAS, 2017, p. 107). Sendo assim, o que podemos perceber são tentativas de criar sentidos para o currículo, baseado na organização de conteúdos que seriam úteis para a vivência no mundo contemporâneo.

Nessa tentativa de conceber noções fundamentais a serem ensinadas e, portanto, passíveis de organização por via do currículo, vemos o movimento realizado em defesa da BNCC como ação que visa constituir consensos que sustentem a seleção de conhecimentos entendidos como essenciais para o aprendizado, buscando definir a identidade do currículo para a educação básica (LOPES, 2015).

Essa tentativa de fixação de sentidos do currículo por meio da gestação da noção de essencialidade própria se apresenta para nós como uma construção precária, uma vez que Hall nos apresenta que as identidades não são algo em si, mas formuladas em contextos de identificações subjetivas (HALL, 2015). Portanto, a ideia de essencialidade que se busca construir em volta da BNCC é uma construção discursiva daquilo que se defende, buscando consolidar sobre a Base a plenitude de sentidos responsáveis por elegê-la como demanda popular (LACLAU, 2005).

Nesta constituição discursiva, os defensores da BNCC trabalham para a formulação de ideias hegemônicas sobre o currículo, aproveitando as lacunas epistemológicas das discussões curriculares para preenchê-las com significados que lhes pareçam alcançar maiores espaços de aceitação (LACLAU; MOUFFE, 2015). É esta construção discursiva que 
nos propomos discutir, nos valendo da análise do ciclo de políticas de Ball e Bowe (1998), no qual trabalhamos com três contextos de produção de políticas:

[...] o contexto da influência, no qual as definições e os diversos discursos políticos são iniciados e/ou construídos; o contexto de produção de textos, em que os textos com as definições políticas são produzidos; e o contexto da prática, no qual as definições curriculares são recriadas e reinterpretadas. (ABREU; LOPES, 2006, p. 183-184).

Seguindo o caminho do ciclo de políticas, discutimos os discursos em prol da BNCC realizados pelos seus defensores no contexto da influência por via de análises das falas propagadas pelo Movimento pela Base Nacional Comum (MBNC) e Governo Federal; posteriormente analisamos os sentidos produzidos para a disciplina de História no contexto da produção de texto por meio do estudo da BNCC, e como esta apresenta os conteúdos de História; por fim analisamos as perspectivas que os professores de História têm sobre as implicações que a Base trará para o currículo da disciplina no contexto da prática.

Nossa opção por esse caminho se deu por entendermos que a política curricular é produzida em múltiplos contextos, nos quais os significados são produzidos em diversos ciclos de produção de política (LOPES, 2006). Sendo assim, para entendermos as interpretações que os professores de História fazem de como a BNCC irá implicar no currículo da disciplina, buscamos interpretar as produções de sentidos sobre o currículo nas esferas que compõem o ciclo de políticas, para que assim possamos nos aprofundar em como se está dando a tradução sobre a BNCC no contexto da prática.

\section{BNCC no contexto de influência}

O governo brasileiro, ao divulgar a Base Nacional para o Ensino Médio, trouxe no texto oficial pontos de defesa à garantia de aprendizagens necessárias a cada cidadão (BRASIL, 2017). Ao apresentar assim a BNCC, acredita-se ser capaz de delimitar um currículo essencial para a formação humana. Contudo, acreditamos que essa noção de essencialidade que se busca para a Base configura-se como uma construção discursiva, cujo processo teve sua gestação montada no contexto de influência, onde atuam não só as instituições e indivíduos ligados ao governo, mas uma gama de agentes interessados em delimitar as linhas que compõem a política oficial (BALL, BOWE, 1998). Nesse contexto, "grupos de interesse disputam para influenciar a definição das finalidades sociais da educação e do que significa ser educado” (MAINARDES, 2006, p. 20).

Em nossa discussão sobre as disputas para influenciar as ideias de currículo que compõem a Base, analisamos discursos que capitanearam os debates em defesa da Base partindo da sociedade civil por meio do MBNC. Optamos por essa instituição devido à centralidade de seus discursos em volta da defesa da normatividade educacional por meio do currículo, ideia essa central à noção de Base, sendo um movimento com amplo apoio de 
instituições privadas agindo em defesa da BNCC, nos permitindo observar processos de governança sobre a instituição da política de currículo proposta pela Base.

Esse processo de governança leva à formulação de políticas ligadas a jogos particularistas de poder, em espaços onde fronteiras que dividem Governo e sociedade tornam-se opacas e novas vozes surgem trazendo suas particularidades para as disputas políticas, tentando induzir a constituição de políticas mediante suas demandas (BALL, 2014), por meio de trabalho em redes que buscam tratar problemas vistos como impossíveis de serem solucionados por via de tratamento gerencial-empresarial (BALL, 2014).

Como exemplo de rede de trabalho em governança para a aprovação da BNCC, temos o MBNC que, como podemos ver, mantém associação com empresas e institutos privados ligados à educação (Figura 1).

Figura 1: Apoio institucional do Movimento Pela Base Nacional Comum.

\begin{tabular}{l|c|c}
\hline \multicolumn{1}{c|}{ Institutos e Fundações privadas } & $\begin{array}{c}\text { Associações e } \\
\text { Conselhos }\end{array}$ & Bancos \\
\hline Cenpec & Abave & Itaú BB \\
\hline Comunidade Educativa CECAD & Consed & \\
\hline Fundação Lemann & Undime & \\
\hline Fundação Maria Cecilia Souto Vidigal & & \\
\hline Fundação Roberto Marinho & & \\
\hline Instituto Ayrton Senna & & \\
\hline Instituto Inspirare & & \\
\hline Instituto Natura & & \\
\hline Instituto Unibanco & & \\
\hline
\end{tabular}

Fonte: Quadro elaborado pelos autores com base em informações do site oficial do Movimento Pela Base Nacional Comum.

O MBNC defende uma educação de qualidade como direito humano e projeto de desenvolvimento nacional, para isso, o Movimento acredita que a Base “[...] deve necessariamente ser apoiada por amplo espectro de agentes públicos e privados [...]” (BASE, 2017). Associando-se a essas intuições, o Movimento traz para si o no hall empresarial de resultados baseados em eficiência e eficácia como chancela de suas discussões, o que vem a ser corroborado pela associação a comunidades epistêmicas de forma a trazer aporte acadêmico de legitimação à Base.

As comunidades epistêmicas são formadas por profissionais que produzem textos e fazem circular ideias com supostas soluções para problemas educacionais (LOPES, 2004), formando grupos em defesa de ideais em volta da educação, objetivando montar um pensamento hegemônico (LACLAU, 2005), atuando em “[...] processos de formação de agenda e difusão de conhecimentos, em escala global/regional/local, em especial, na 
produção de consenso como base para coordenação de políticas, extrapolando o conhecimento técnico-científico.” (DIAS, 2017, p. 104).

A rede montada em volta do MBNC articulou pessoas atuantes em diversos centros produtores de política, totalizando em seu site oficial ${ }^{1}$ o nome de 63 indivíduos, os quais apresentam as seguintes ligações institucionais:

Figura 2: Ligações institucionais das pessoas que compõem o Movimento Pela Base Nacional Comum.

\begin{tabular}{lc}
\multicolumn{1}{c}{ Instituições às quais os apoiadores do MPBNC estão ligados. } & Qtd. \\
\hline Associação Brasileira de Editores de Livros Escolares (Abrelivros) & 1 \\
\hline Confederação Nacional de Municípios & 1 \\
\hline Escola Pública & 1 \\
\hline Instituição de Ensino Superior Internacional & 1 \\
\hline $\begin{array}{l}\text { Instituto Nacional de Estudos e Pesquisas Educacionais Anísio Teixeira } \\
\text { (INEP) }\end{array}$ & 1 \\
\hline Secretaria do Meio Ambiente & 1 \\
\hline Serviço Social do Comércio (SESC) & 1 \\
\hline Governo Estadual & 1 \\
\hline União Nacional dos Dirigentes Municipais de Educação (Undime) & 2 \\
\hline Câmara dos Deputados & 4 \\
\hline Instituição de Ensino Superior Pública & 3 \\
\hline Conselho Nacional de Educação (CNE) & 4 \\
\hline Instituição de Ensino Superior Privada & 5 \\
\hline Instituição Financeira & 5 \\
\hline Ministério da Educação (MEC) & 6 \\
\hline Organizações não governamentais (ONG) e Organizações da Sociedade & 6 \\
\hline Civil de Interesse Público (OSCIP) & 7 \\
\hline Secretarias de Educação & 13 \\
\hline Institutos e Fundações com pautas educacionais & $\mathbf{6 3}$ \\
\hline
\end{tabular}

Fonte: Quadro elaborado pelos autores com base em informações do site oficial do Movimento Pela Base Nacional Comum.

A partir da Figura 2 observamos ampla participação de Institutos e Fundações que atuam em parceria com governos estaduais e municipais, fornecendo capacitações e materiais didáticos, tendo em alguns casos a ligação direta com empresas, como é o caso da Fundação Lemann e Instituto Natura. Essa ligação com o setor privado amplia-se ao observarmos a presença de membros de organismos ligados a instituições financeiras (Itaú Unibanco e Banco Mundial) presentes no embasamento das discussões propostas pelo Movimento. 
No que diz respeito ao campo diretamente educacional, o Movimento acercou-se por membros de órgãos governamentais nos âmbitos federais, estaduais e municipais, como o MEC, INEP, CNE, Undime, Secretarias de Educação estaduais e municipais, além de docentes atuantes no Ensino Superior. Soma-se a esse panorama, a atuação no campo político de Deputados e um Vice-governador.

Podemos perceber a partir dos levantamentos apresentados nas Figuras 1 e 2, o fortalecimento em defesa da Base em diferentes espaços compondo o ciclo de influência, utilizando-se de comunidades epistêmicas que trazem consigo força financeira capaz de publicizar suas ideias, de forma a montarem com o auxílio de especialistas em educação discursos palpáveis de aceitação. Contudo, a implantação de suas ideias precisa da legitimidade democrática, o que foi trabalhado com os dados gerados por ações capitaneadas pelo MEC, que visaram sancionar a proposta da Base, com isso

O discurso celebratório dos grandes entusiastas da BNCC - o MEC e institutos e fundações empresariais como a Lemann - tem sido acompanhado por uma série de dados que comprovariam as virtudes democráticas do processo de construção da Base, notadamente as 12 milhões de contribuições oriundas da consulta pública on-line à primeira versão do documento, coletadas entre outubro de 2015 e março de 2016. (CÁSSIO, 2017).

Somam-se às contribuições via internet a realização de 5 audiências públicas realizadas entre julho e setembro de 2017 em cada região do país, e mais de 27 seminários estaduais. Com esses números o MBNC defende a ideia de processo democrático na organização da BNCC, construindo assim, por meio de sua rede de articulações discursos de legitimação de uma Base constituída democraticamente e que viria a garantir as aprendizagens necessárias aos alunos do Ensino Médio de todo o Brasil, defendendo desta forma o currículo prescritivo como garantia de qualidade educacional.

Essas ideias apresentadas pelo MBNC não reverberaram com anuência entre entidades científicas, como foi o caso da Associação Nacional de Pós-Graduação e Pesquisa em Educação (ANPED) e a Associação Brasileira de Currículo (ABdC), bem como entidades sindicais como a Confederação Nacional dos Trabalhadores em Educação (CNTE), as quais vieram se posicionar contrárias à ideia de Base Nacional e sua implantação. Em termos específicos disciplinares, a Associação Nacional de História (ANPUH) publicou no dia 01 de agosto de 2018 em sua página no Facebook, nota oficial posicionando-se contrária à BNCC e à Lei 13.415/2017 (Lei da reforma do Ensino Médio), considerando ambas como de aplicação antidemocráticas e contrárias à defesa da educação de qualidade (ANPUH, 2018).

Apesar de sofrer críticas, a BNCC foi aprovada inicialmente para os Ensinos Infantil e Fundamental, homologada em 20 de dezembro de 2017. Para o Ensino Médio foram realizadas audiências públicas de maio a setembro de 2018, visando legitimar e proporcionar um certo ar democrático quanto a construção da Base, a qual veio a ser homologada em 14 de dezembro de 2018. 


\section{BNCC do ensino médio no contexto da produção de texto}

Para realizar nossa análise sobre a produção de sentidos sobre a BNCC no contexto da produção de texto, optamos em trabalhar diretamente com a proposta oficial da BNCC para o Ensino Médio, que foi apresentada e homologada em dezembro de 2018, a qual não trouxe alterações significativas à proposta apresentada e disponibilizada para consulta durante o período de audiências públicas. A BNCC traz em seu corpo, textos que apresentam o que é a ideia de Base, como esta foi pensada, caracteriza as etapas de ensino e delimita as competências e habilidades específicas por disciplinas.

Seguindo o caminho discursivo do MBNC, o texto da BNCC defende a ideia de que a Base traz em seu corpo uma organização articulada e coerente de saberes pautados em direitos de aprendizagem em consonância com experiências educativas em nível global, voltadas para a elevação da equidade e qualidade do ensino (BRASIL, 2017). Para isso, a Base é apresentada como "documento de caráter normativo que define o conjunto orgânico e progressivo de aprendizagens essenciais que todos os alunos devem desenvolver ao longo das etapas e modalidades da Educação Básica” (BRASIL, 2017, p. 7), pois “explicita as aprendizagens essenciais que todos os estudantes devem desenvolver” (BRASIL, 2017, p. 15), esperando que com isso se supere a fragmentação de políticas educacionais, auxiliando as redes e sistemas educacionais a garantirem patamares comuns de aprendizagens aos estudantes.

Na construção do discurso oficial via documento da Base, percebemos essa preocupação em trazer para a BNCC a capacidade de condensar os conhecimentos em sua essência, como garantidores de melhorias para a educação. Vemos com preocupação esses dois pontos, primeiro porque identificamos dentro do contexto educacional a quebra de qualquer possibilidade de essencialidade dos saberes, saberes estes incapazes de se legitimarem a partir de metanarrativas, necessitando estabelecerem interligações utilitaristas de acordo com os contextos de demandas vigentes, as quais ainda passam pela disputa disciplinar de estudiosos em luta por determinarem a importância de suas áreas de conhecimento de forma a legitimarem sua presença nos currículos. (LYOTARD, 2009).

O segundo ponto refere-se às garantias de educação de qualidade via currículo. Em seu texto oficial, tem-se a defesa da Base como artífice garantidor dessa qualidade e equidade educacional, realizando desta feita uma ligação simplista, onde o currículo de qualidade garantiria a educação de qualidade, porém, há de se problematizar essa aparente obviedade (LOPES, 2012), pois o que temos é a tentativa de hegemonização sobre os significados construídos pela Base de currículo essencial, por meio de articulações hegemônicas que tentam estabelecer centros de essencialidades provisórias para uma estrutura falida (LOPES 2012).

Podemos perceber isso ao encontrarmos ambivalência no texto da BNCC, marcando a presença de discursos com sentidos variados (DIAS, 2009), situação essa até mesmo esperada, uma vez que o texto político é marcado pela heterogeneidade, devido às múltiplas 
mãos que trabalharam em sua escrita, como pela tentativa de alcançar um público amplo para sua aceitação.

Vemos nessas ambivalências na BNCC em torno do seu centro de discussão a orientação de um currículo nacional, em várias partes do texto o que se coloca é que a Base, de acordo com Mendonça Filho - Ministro da Educação em exercício quando da publicação da BNCC - com sua homologação “[...] o País estará finalmente dotado de uma Base Nacional Comum para a elaboração dos currículos de todas as etapas da Educação Básica” (BRASIL, 2017, p. 5), atuando na organização curricular do Ensino Médio, a qual na atualidade apresenta-se com "[...] excesso de componentes curriculares, e uma abordagem pedagógica distante das culturas juvenis e do mundo do trabalho.” (BRASIL, 2017, p. 46).

Na BNCC a educação deve voltar-se para o reconhecimento das transformações dos contextos nacionais e internacionais observando as demandas que essas mudanças geraram, para a partir daí operar na educação. A forma como é apresentada essa ideia nos passa um pensamento marcado pelo pragmatismo, limitando os conhecimentos de acordo com a utilidade, distanciando o aluno da formação holística e humanista, indo justamente na contramão da educação de qualidade marcada pela equidade.

Outro ponto em questão são as afirmações paradoxais entre dizer que a Base orientará a elaboração de currículos e posteriormente afirmar que para o Ensino Médio a BNCC “[...] não se constitui no currículo dessa etapa, mas define as aprendizagens essenciais a ser garantidas a todos os estudantes e orienta a (re)elaboração de currículos e propostas pedagógicas” (BRASIL, 2017, p. 471), podemos perceber as ambivalências dentro da mesma sequência do texto. Devemos lembrar que mesmo a Base não sendo o currículo, essa apresenta-se de forma a exercer poder sobre este, construindo a realidade e constrangendo comportamentos por via da projeção de identidade e sentidos (LOPES, MACEDO, 2011), uma vez que concordamos com Lopes e Macedo (2011) ao entendermos os "[...] discursos pedagógicos e curriculares como atos de poder, o poder de significar, de criar sentidos e hegemonizá-los.” (LOPES, MACEDO, 2011, p. 40).

Desta feita, a Base contando com o apoio institucional do Governo Federal, MEC, de membros do legislativo em esferas federais e estaduais, grupos da sociedade civil, instituições financeiras diretas ou por meio de seus braços metamorfoseados em fundações e institutos, podemos ver como a escrita de um texto longo e ambivalente passa a ser defendido de forma a hegemonizar o discurso em prol da educação, onde o discurso apoiado “[...] sobre um suporte e uma distribuição institucional, tende a exercer sobre os outros discursos [...] uma espécie de pressão e como que um poder de coerção.” (FOUCALT, 2014, p. 17).

Com o uso da força institucional, financeira e a chancela de grupos da sociedade civil, vemos no texto da BNCC o aproveitamento de espaços sem preenchimentos para apresentar a Base como demanda popular. Entendendo demanda não como um ponto referencial de um dado grupo social, pelo contrário, as demandas permeiam os grupos e essas demandas ao somarem-se encontram acolhimento em grupos que se associam mediante a interseção de pontos de pautas, por serem amplas as pautas e diferentes os grupos temos a existência de assimetrias entre os grupos (LACLAU, 2005). 
Nesse jogo de aproximações e distanciamentos temos espaços de equivalências onde os grupos elegem pontos de pauta a serem elevados ao topo da defesa de seus interesses, encarnando a plenitude ausente por meio da cadeia de equivalência (LACLAU, 2005). Com isso busca-se fazer com que as pessoas fora do grupo de discussão passem a ver determinadas pautas como demandas coletivas, dessa forma, se tornaria uma demanda popular que se espalharia pelo seio da sociedade representando um anseio geral da população.

Contudo, não é o que podemos perceber quando analisamos as falas de professores atuantes no Ensino Médio, os quais sentem-se distantes das propostas apresentadas na BNCC. Quando falamos em professores, estamos nos reportando aos professores de História e com isso devemos lembrar que a História na BNCC para o Ensino Médio aparece como parte da Área de Ciências Humanas e Sociais Aplicadas, juntamente com as disciplinas de Geografia, Sociologia e Filosofia, não constando de espaço próprio para suas definições. Por sinal somente as disciplinas de Matemática e Língua Portuguesa são contempladas por definições próprias, mostrando a preocupação da Base com as duas disciplinas centrais para as avaliações de larga escala. Dessa forma, a História juntamente com as demais disciplinas

de sua Área são regidas por competências e habilidades que tentam normatizar o trabalho da Área.

Esse processo e diluição da História, suas metodologias e teorias próprias da disciplina têm impacto no modo como os professores de História entendem a Base e como esta trará implicações para o currículo da disciplina.

\section{BNCC na perspectiva do contexto da prática}

Realizadas nossas análises sobre a BNCC no que diz respeito às articulações traçadas no contexto de influência, e a busca por fixar significados hegemônicos por via do texto normativo, analisaremos agora o que pode ser observado sobre as percepções docentes ligadas a projeções de futuras implicações da BNCC para o currículo de História no contexto da prática.

Quando nos referimos ao contexto da prática estamos falando de espaços onde os professores interpretam as políticas - desde sua gênese no contexto de influência passando pelas normativas estabelecidas no contexto da produção de texto - e estabelecem relações com suas práticas (MAINARES, 2006), criando microcosmos políticos (OLIVEIRA; LOPES, 2011) decidindo aquilo que devem aplicar (BALL; BOWE, 1998) de acordo com a realidade vivenciada, realizando escolhas e dando significados à política de acordo com suas próprias demandas. Dessa forma, o contexto da prática não se caracteriza como um local de implementação de políticas, mas espaço de ressignificações e disputas políticas tão acirradas quanto os demais contextos, capaz de influenciá-los de forma tão forte como estes ao contexto da prática, em movimentos contínuos de política.

Para nossa análise, trabalhamos com seis professores de História que lecionam entre a rede pública e privada de Ensino Médio. Essa mostra foi montada a partir do envio de questionários abertos a vinte professores no dia 31 de julho de $2018^{2}$, dos quais seis 
responderam de forma anônima entre os dias 31 de julho e 03 de agosto do mesmo ano, identificando a cidade onde exercem docência, a rede de ensino a qual estão ligados e o tempo de profissão, as demais perguntas já se direcionaram a entender as percepções destes professores sobre a Base.

Nossa mostra ficou distribuída com professores que atuam em três mesorregiões cearenses $^{3}$ : a Região Metropolitana de Fortaleza - 1 professor da cidade de Fortaleza; Região Norte Cearense - 1 professor da cidade de Itapipoca e Região Noroeste Cearense - 1 professor da cidade de Massapê e 3 professores da cidade de Sobral. Entre os docentes, cinco são da rede pública e um da rede privada, os quais têm tempo médio de experiência em sala de aula de oito anos, em que o mais novo tem dois anos de docência e o mais experiente doze anos.

Com esta amostragem passamos a analisar as construções discursivas da BNCC e a vivência dos professores no contexto da prática, iniciando com a discussão em torno da participação dos docentes na construção da BNCC. No contexto de influência, os entusiastas da Base ligados ao MBNC difundiram o discurso de ampla e democrática participação dos profissionais da educação, visão esta reforçada pelo então secretário de Educação Básica do MEC, Manuel Palácios, para o qual mais de 1 milhão de professores teriam participado com contribuições via internet para a BNCC (CÁSSIO, 2017), número este questionado por Cássio (2017), levando em conta projeções de escala e baseado nos microdados da consulta pública, além do que a realização do cadastro na plataforma on-line projetada para a Base não significa que esses cadastros tenham se transformado em contribuições, sendo necessário “[...] qualificar o que se chama de 'contribuição”” (CÁSSIO, 2017).

Esse contrassenso entre ampla participação apresentada no discurso e dados do contexto da prática nos é percebida ao vermos que metade dos respondentes do questionário não participaram das discussões em torno da construção da BNCC, e os demais participaram em diferentes graus, um com ampla atuação, pois de acordo com sua fala: “além de organizar as discussões na unidade escolar que trabalho, também representei os professores de História na plenária regional em 2016.” (Prof. 4), enquanto o Prof. 5 participou ainda das discussões realizadas durante o governo Dilma Roussef com a leitura e crítica do projeto inicial apresentado (Prof. 5) e o Prof. 6 opinou sobre o conteúdo a ser lecionado. Com isso vemos dentro de nossa amostragem uma situação na qual a amplidão de participação nas discussões sobre a BNCC não se concretiza.

A título da democratização em torno das contribuições vemos cinco dos professores afirmarem que não se sentem contemplados pela BNCC e o Prof. 5 apresenta que seu entendimento se dá pois pensa que “o perfil técnico apresentado pela proposta acaba por privilegiar uma perspectiva não reflexiva para os alunos. Eles não desenvolvem a crítica e, muito menos, o reconhecimento político e social.” (Prof. 5). O posicionamento apresentado pelo docente é complementado pela fala do Prof. 4, que acredita ter na Base pontos interessantes, contudo “o arcabouço estrutural produzido pela lei 13.415/17, junto a uma ideia de direitos individuais de aprendizagem que desarticula o saber escolar e a realidade social, é extremamente preocupante.” (Prof. 4). Vale lembrar que a lei 13.415/17 reorganiza o Ensino Médio, passando somente as disciplinas de Língua Portuguesa e Matemática a serem 
componentes curriculares obrigatórios para as três séries do Ensino Médio, o que faz com que a História perca espaços de discussão no ambiente escolar.

O único professor a sentir-se contemplado pela Base afirmou que com “a flexibilização das disciplinas (para que o estudante estruture sua grade também) atende um anseio de tirar o inchaço de conteúdos.” (Prof. 3). Percebemos nessa fala do professor um alinhamento ao discurso oficial e aos pontos de defesa do MBNC, valorizando o currículo prático e enxuto. Esta visão pode estar associada à ligação do docente com a rede privada de ensino, uma vez que o docente acredita ter semelhanças entre a Base e as exigências do ENEM, esse exame é trabalhado exaustivamente pela rede privada em dinâmicas de performatividade.

Quando adentramos nas questões específicas para o currículo de História, percebemos críticas contrárias à apresentação realizada pela BNCC permearem as falas dos docentes. Devemos lembrar que a Base para o Ensino Médio não contemplou a História como disciplina isolada, as orientações para a História foram realizadas de forma genérica para as demais disciplinas da Área de Ciências Humanas, organizadas em competências e habilidades, ficando a cargo do professor a organização dos conteúdos para darem conta dos objetivos traçados pela Base. Dessa forma, quando falamos em História na BNCC do Ensino Médio estamos relacionando como os professores de História entendem como essas competências e habilidades podem influenciar no trabalho da disciplina.

As falas dos professores caminham para duas categorias de críticas, uma voltada para o desenho pragmático da seleção de conhecimentos e a outra para a supressão de discussões. O pragmatismo foi apontado por professores como problema responsável por dar ares utilitaristas de mercado à disciplina, distanciando a História do caráter crítico e limitando a constituição da consciência histórica. Podemos ver esse tipo de visão a partir de duas falas:

Percebo que a proposta expõe fundamentos pedagógicos guiados por uma diretriz pragmática, utilitária e de fundo liberal buscando formar mão de obra para o mercado de trabalho e sem o aparato crítico. Uma tentativa de controlar e mecanizar o ensino de História. (Prof. 1)

Como todo currículo prescritivo, é uma visão, uma ação de poder que acaba por limitar o trabalho de construção da consciência histórica, refletindo conteúdos em detrimento a objetivos de aprendizagem, estando essa, vinculada também, apenas a uma necessidade de cumprir currículo avaliativo. (Prof. 4)

Pelas percepções dos dois docentes, podemos ver a preocupação quanto à redução da História a conhecimentos com viés utilitários, distanciando o trabalho da disciplina de sua constituição crítica, responsável por questionar e analisar as construções históricas responsáveis por auxiliarem na interpretação sobre a realidade, além de apontar para a preocupação com o mero fato de cumprir currículos que no final se ligam ao preparo para marcações de questões em avaliações.

Quanto à redução do currículo realizado pela Base temos duas perspectivas, uma que vê a limitação de conteúdos ligados à perspectiva eurocêntrica poder privilegiar o trabalho com temas identitários sobre a história. Contudo, sobre este aspecto de limitação de conteúdos o 
que se sobressai é a preocupação quanto a esta seleção realizada e a "supressão de certos conteúdos, em detrimentos de outros” (Prof. 6), além da utilização de “palavras ambíguas em áreas temáticas que estão em palco de disputa políticas na atualidade” (Prof. 3). Como apresentado pelo Prof. 3, o que temos são espaços de disputas, essas lutas por conferir significados ao currículo trouxe para os docentes entrevistados visões em sua maior parte negativas quanto à apresentação das diretrizes da Base que deverão pautar a organização do currículo de História para o Ensino Médio.

Concluímos nosso questionário perguntando aos professores qual seria a projeção sobre as implicações que a BNCC irá trazer para o currículo de História no contexto da prática. Enquanto no contexto de influência e da produção de texto se tem a defesa da Base como orientação palpável para a organização de currículos de qualidade, os professores apresentam projeções pessimistas quanto às implicações da BNCC, vendo-a como elemento que trará superficialidade e engessamento para o currículo de História, contrariando os discursos dos defensores da Base e do próprio texto oficial de proposta da BNCC para o Ensino Médio.

Essa visão de superficialidade que a Base trará fica clara na fala do Prof. 1 e é corroborada na observação do Prof. 3 ao afirmarem que:

Ocorrerá o esvaziamento do significado do ensino de História, não permitindo que o aluno consiga fazer as conexões entre as temáticas históricas devido ao fatiamento excessivo dos conteúdos e a criação de proximidades temporais inexistentes. (Prof. 1)

Penso que alguns temas podem sofrer uma espécie de relativismo por conta, paradoxalmente, da flexibilização. Mesmo que o currículo mencione o respeito à diversidade, noto que pode haver um privilégio de temas que fundamentem uma estrutura dominante. (Prof. 3)

O que vemos nas falas dos professores projeta a perca de criticidade em torno da História como disciplina para o Ensino Médio, devido ao esvaziamento de significados e ao fatiamento excessivo de conteúdos (Prof.1). Como sabemos, o currículo é montado a partir de seleções realizadas em diferentes contextos e “[...] no qual são protocolados e sancionados modos específicos de representação, de conteúdos e de relações, enquanto outros são excluídos e nem formulados” (CORAZZA, 2001, p. 15). Esta seleção realizada pela Base é motivo de crítica pelos professores, pois além da superficialidade, os Professores 4 e 5 apontam para o engessamento e desvalorização dos docentes com a BNCC.

O Prof. 4 acredita que a Base proporcionará “o empobrecimento do trabalho pedagógico, ou mesmo sua superficialidade, o engessamento do fazer docente, bem como o distanciamento da reflexão” (Prof. 4), enquanto o Prof. 5. acredita que a base tende a "produzir uma desvalorização do docente de História e da disciplina em si, bem como uma formação precária no tocante à crítica, identidade e participação política.” (Prof. 5). Vemos que entre os professores pesquisados não se percebe a Base como elemento que venha auxiliar ou qualificar o currículo ou o trabalho docente, pelo contrário, esta é vista como 
elemento de empobrecimento do currículo para o Ensino Médio e com impactos na desvalorização docente.

\section{Considerações finais}

A BNCC foi cercada por discursos voltados a demarcarem espaços de centralidade para o currículo como elemento de garantias de qualidade e equidade para a educação. Esses discursos partiram de diferentes contextos de políticas, defendendo um currículo que pudesse assegurar as aprendizagens necessárias e essenciais a cada cidadão. Para isso, a Base contou com uma gama de agentes interessados em delimitar linhas políticas e finalidades da educação em processos de governança, minando as linhas demarcatórias entre o público e o privado.

No movimento em prol da Base vimos como o MBNC se agrupou em torno de uma rede de governança com poderes financeiros e empresariais capazes de chancelarem por via da gerência empresarial de resultados a necessidade de uma Base. Já no campo legislativo pudemos observar no texto da BNCC as ambivalências em torno do que seria a delimitação curricular para o Ensino Médio. Em ambos os casos, a Base é defendida como garantia da qualidade e equidade educacional, montada a partir de princípios democráticos de ampla participação.

Ao adentrarmos no campo do contexto da prática, vemos o quanto os discursos montados nos contextos de influência e da produção de texto, que ganharam notoriedade e foram responsáveis pela formulação da BNCC homologada, encontram-se distantes dos profissionais em sala de aula. Nesse distanciamento entre os discursos de defesa da Base e as visões que os professores têm da BNCC vemos um grande lapso, onde os docentes não concebem a Base como democrática e muito menos capaz de garantir a qualidade e equidade educacional, pelo contrário, os docentes percebem que a Base vem, no campo da História, para desqualificar o trabalho crítico da disciplina e desvalorizar seus profissionais.

Seguindo a análise do ciclo de política, ao entender o contexto da prática como microcosmo próprio do fazer político, somos levados a acreditar que os professores tendem a subverter a Base, por não a considerarem um auxílio para o trabalho docente, pelo contrário, ela é entendida como um entrave. Enquanto os defensores da BNCC afirmam a qualidade de nortear o trabalho docente em volta dos conhecimentos tidos como necessários, os professores de História apontam para o lado oposto, vendo o currículo de História a partir da Base como superficial e engessado, mostrando assim o quanto é falida a ideia de essencialidade para o currículo e, levando em conta o poder político do fazer docente em sala de aula, que se mostra contrário à Base, tende também a BNCC a ser falida.

\section{Notas}

1. Vide: http://movimentopelabase.org.br/quem-somos 
2. O trabalho de coleta de dados com os professores foi realizado durante o período de análise e audiências públicas em torno da BNCC para o Ensino Médio, contudo o texto aprovado em dezembro de 2018 não trouxe significativas alterações a proposta apresentada, a qual os professores tiveram acesso, tirando suas conclusões a partir desse texto.

3. O Ceará conta com sete mesorregiões delimitadas pelo IBGE, que levam em conta o processo social, o quadro natural e a rede de comunicação e lugares com o intuito de possibilitar a delimitação de identidade regional. (CEARÁ, 2015).

\section{Referências}

ABREU, Rozana Gomes de. Políticas de Currículo para o Ensino Médio no Rio de Janeiro: o caso da disciplina Química. In.: Contexto e Educação. ano 21, n. 76. Ijuí: Editora Unijuí, p. 175 - 200, 2006. Disponível em: https://www.revistas.unijui.edu.br/index.php/contextoeducacao/article/view/1102. Acesso em: 15 jul. 2018.

ANPUH. Pela revogação da Lei de reforma do Ensino Médio (Lei 13.415/2017) e retirada da proposta de Base Nacional Comum Curricular (BNCC). 2018. Disponível em: https://www.facebook.com/ANPUH/photos/a.320837787947761.80998.116800045018204/201191505884 0017/?type=3\&theater. Acesso em: 01 ago. 2018.

BALL, Stephen. \& BOWE, Richard. El currículumnacional y su "puestaenpráctica”:

El papel de los departamentos de materias o asignaturas. In.: Revista de Estudios de

Currículum. vol. 1, nº 2, p.105-131, 1998.

BALL, Stephen. Educação Global S.A.: novas redes políticas e o imaginário neoliberal. Ponta Grossa: UEPG, 2014.

BRASIL. Lei 12.796 de 2013. Disponível em: http://www.planalto.gov.br/ccivil_03/_ato20112014/2013/lei/l12796.htm. Acesso em: 13 jul. 2018.

BRASIL. Base Nacional Comum Curricular - Ensino Médio. 2017. Disponível em: http://basenacionalcomum.mec.gov.br/wpcontent/uploads/2018/06/BNCC_EnsinoMedio_embaixa_site_110518.pdf. Acesso em: 01 ago. 2018.

CÁSSIO, Fernando. Participação e participacionismo na construção da Base Nacional Comum Curricular. In.: $\begin{array}{llllll}\text { Nexo Jornal. } & 02 & \text { dez. } & 2017 . & \text { Disponível }\end{array}$ https://www.nexojornal.com.br/ensaio/2017/Participa\%C3\%A7\%C3\%A3o-e-participacionismo-naconstru\%C3\%A7\%C3\%A3o-da-Base-Nacional-Comum-Curricular. Acesso em: 03 ago. 2018.

CEARÁ. As regiões de planejamento do Estado do Ceará. In.: Textos para discussão. n. 11, 2015. Disponível em: http://www.ipece.ce.gov.br/textos_discussao/TD_111.pdf. Acesso em: 10 ago. 2018.

CORAZZA, Sandra. O que quer um currículo? Pesquisas pós-críticas em Educação. Petrópolis: Editora Vozes, 2001.

DIAS, Rosanne Evangelista. Ciclo de políticas curriculares na formação de professores no Brasil (1996 2006). 2009. 248 f. Tese (Doutorado em Educação) - Faculdade de Educação, Universidade do Estado do Rio de Janeiro, Rio de Janeiro, 2009. Disponível em: http://www.curriculouerj.pro.br/imagens/pdfTeses/CICLO_DE_P_71.pdf. Acesso em: 25 maio 2018.

DIAS, Rosanne Evangelista. Currículo, docência e seus antagonismos no espaço iberoamericano. In.: Revista Investigación Cualitativa, n. 02. p. 100 - 114, 2017. Disponível em:

https://ojs.revistainvestigacioncualitativa.com/index.php/ric/article/view/67. Acesso em: 15 jul. 2018.

FOUCALT, Michel. A ordem do discurso: aula inaugural no Collège de France, pronunciada em 2 de dezembro de 1970. 24. ed. São Paulo: Loyola, 2014.

HALL, Stuart. A identidade cultural na pós-modernidade. Rio de Janeiro: Lamparina, 2015. 
LACLAU, Ernesto. La razón populista. Buenos Aires: FCE, 2005.

LACLAU, Ernesto; MOUFFE, Chantal. Hegemonia e estratégia socialista: por uma política democrática radical. São Paulo: Intermeios; Brasília: CNPq, 2015.

LOPES, Alice Casimiro. Políticas curriculares: continuidade ou mudança de rumos? In.: Revista Brasileira de Educação. n. 26, 2004. Disponível em: http://stoa.usp.br/gepespp/files/3114/17469/Pol\%C3\% ADticas+curriculares+-+continuidade+ou+mudan\%C3\%A7a+de+rumos.pdf. Acesso em: 01 ago. 2018.

LOPES, Alice Casimiro. Discursos nas políticas de currículo. In.: Currículo sem Fronteiras. v. 6. n. 2. 2006. Disponível em: http://www.curriculosemfronteiras.org/vol6iss2articles/lopes.pdf. Acesso em: 15 jul. 2018.

LOPES, Alice Casimiro; MACEDO, Elizabeth. Teorias de currículo. São Paulo: Cortez, 2011.

LOPES, Alice Casimiro. A qualidade da Escola Pública: uma questão de currículo? In: A qualidade da escola pública no Brasil. VIANA, Fabiana da Silva [et al]. Belo Horizonte: Mazza Edições, p. 13 - 29, 2012.

LOPES, Alice Casimiro. Por um currículo sem fundamentos. In.: Linhas Críticas. v. 21. n. 45. Brasília. p. 445 - 466, 2015. Disponível em: http://periodicos.unb.br/index.php/linhascriticas/article/view/16735. Acesso em 15 jul. 2018.

LYOTARD, Jean-François. A condição pós-moderna. 12a ed. Rio de Janeiro: José Olympio, 2009.

MAINARDES, Jefferson. Abordagem do ciclo de política: uma contribuição para a análise de políticas educacionais. In.: Educação e Sociedade. v. 27, n. 94. Campinas, p. 47-69, 2006. Disponível em: http://www.scielo.br/pdf/es/v27n94/a03v27n94.pdf. Acesso em: 15 jul. 2017.

OLIVEIRA, Ana de; LOPES, Alice Casimiro. A abordagem do ciclo de políticas: uma leitura pela teoria do discurso. In.: Cadernos de Educação. n. 38.p. 19-41, 2011. Disponível em: https://periodicos.ufpel.edu.br/ojs2/index.php/caduc/article/view/1541. Acesso em: 18 jul. 2018.

\section{Correspondência}

Francisco José Balduino da Silva: Mestre em Ensino (UERN). Professor de História da Rede Pública do Estado do Ceará. Membro do Grupo de Pesquisa Contexto e Educação (CNPq/UERN).

E-mail: professorbalduino@gmail.com

Jean Mac Cole Tavares Santos - Doutor em Educação (UFPB), com Estágio Pós-Doutoral em Educação (UERJ). Professor da Faculdade de Educação (UERN). Coordenador do Grupo de Pesquisa Contexto e Educação (CNPq/UERN). Coordenador do Grupo de Extensão Estudos de Indisciplina e Violência na Escola (EIVE).

E-mail: maccolle@hotmail.com

Márcia Frota Fernandes - Mestre em Educação (IFRN). Professora de Filosofia da Rede Pública do Estado do Ceará. Professora Preceptora da Residência Pedagógica em Filosofia (UVA)

E-mail: marcia.ffrota@gmail.com

Texto publicado em Currículo sem Fronteiras com autorização dos autores 